\title{
Development of formal dynamic models with Microsoft Excel for greenhouse climate control
}

\author{
V. Valiño, A. Perdigones, J. Cerro and J.L. García \\ Polytechnic University of Madrid, Dpto. Ingeniería Rural \\ Avda. Complutense, 28040 Madrid, Spain
}

Keywords: heating, ventilation, cooling, fogging, formal models

\begin{abstract}
Simple climate models performed with a widespread computer tool (Microsoft ${ }^{\circledR}$ Excel) could be useful for researchers or even greenhouse growers. A model of this type was used in three independent studies (heating, ventilation and cooling). The error in the calculation of temperature was lower than $2.5^{\circ} \mathrm{C}$, and the error in the calculation of relative humidity was lower than $9 \%$, in the validation of the model. The main advantage of the method of modelling is the possibility of fitting the coefficients with the tool SOLVER of Microsoft ${ }^{\circledR}$ Excel in each greenhouse, an easy method for both scientist and growers.
\end{abstract}

\section{INTRODUCTION}

Simulation models have been used to estimate the potential of control strategies (de Zwart, 1997; de Halleux and Gauthier, 1998). The availability of computer control systems for environmental management allows better climate conditions to be obtained and therefore greater productivity to be achieved. Improved control algorithms have been found effective for energy saving (Spanomitsios, 2001; Körner and Challa, 2003), and studies to develop humidity controllers related to incident radiation have been undertaken (Zolnier et al., 2000). However, these algorithms and models are generally difficult to adapt for other research teams. Simple models performed with a widespread computer tool (Microsoft ${ }^{\circledR}$ Excel) could be useful for researchers or even greenhouse growers.

\section{MATERIALS AND METHODS}

The experimental greenhouse of Madrid (Spain) had an arch-shaped roof, a steel structure and a single layer cover of metacrylate. The covered soil surface was $132 \mathrm{~m}^{2}$. The height from soil to gutter was $3 \mathrm{~m}$, and the area of metacrylate cover exposed to the outside air was $258 \mathrm{~m}^{2}$. The greenhouse was equipped with four air heaters, side and roof windows, thermal screen and low-pressure fogging system; all the equipment was controlled with timers. Gerbera jamesonii was grown in pots inside the greenhouse. The height of the crop was lower than $0.5 \mathrm{~m}$. Two data acquisition systems (Datataker DT50) were used for recording the climate parameters, essentially temperature and relative humidity. A complete set of the rest of outside climate parameters was supplied by a meteorological station of the University, placed nearby the greenhouse. The heating supply was calculated from the hours of functioning.

Three independent studies (heating, ventilation and cooling) were performed in the same greenhouse using the same climate model. These studies gave as result three Doctoral Thesis, and part of them has been already published (Perdigones et al., 2008). The present work deals with the comparison of the performance of the climate model in the three studies. In all cases, tests were carried out in the heating season 2001/02 and 
summer 2002 for the construction of the climate model, and in the heating season 2002/03 and summer 2003 for the validation of the climate model (Table 1).

\section{Modelling. Energy and mass balances}

A model based in mass and energy conservation equations was developed to evaluate control strategies. In the energy balance, the fluxes considered were the following:

- Energy supplied by heating, $\mathrm{H}\left(\mathrm{W} \mathrm{m}^{-2}\right)$.

- Energy supplied by insolation, $\beta \tau \mathrm{S}$ (insolation $\mathrm{S}, \mathrm{W} \mathrm{m}^{-2}$ ). $\mathrm{B}$, fraction of solar radiation converted into sensible heat (non-dimensional) and $\tau$, transmissivity of the cover (non-dimensional).

- Energy losses through the structure, U (Ti-To). U, overall heat transfer coefficient (closed windows), $\mathrm{W} \mathrm{m}^{-2}{ }^{\circ} \mathrm{C}^{-1}$. Ti, inside temperature $\left({ }^{\circ} \mathrm{C}\right)$, To, outside temperature $\left({ }^{\circ} \mathrm{C}\right)$.

- Energy losses through the open windows, V (Ti-To), with two coefficients for two roof apertures, $25 \mathrm{~cm}$ and $70 \mathrm{~cm}$. V, overall heat transfer coefficient (open windows), $\mathrm{W}$ $\mathrm{m}^{-2} \mathrm{C}^{-1}$.

- Sensible heat converted into latent heat of vaporisation of water by the fog system, $\mathrm{F}$ $\left(\mathrm{W} \mathrm{m} \mathrm{m}^{-2}\right)$.

- Heat capacity of the greenhouse, $\mathrm{C}\left(\mathrm{J} \mathrm{m}^{-2}{ }^{\circ} \mathrm{C}^{-1}\right)$.

Since the energy balance was dynamic, the sum of the energy fluxes could be different from zero in each period; energy was stored or released by the greenhouse thermal mass, affecting the value of the inside air temperature in the next period considered. This first balance supplied the simulated inside temperature of each period calculated from the parameters of the previous period, with the following equation $(\Delta t$, time period in seconds):

$$
\mathrm{Ti}(\text { next period })=\mathrm{Ti}+[\mathrm{H}+\beta \tau \mathrm{S}-\mathrm{U}(\mathrm{Ti}-\mathrm{To})-\mathrm{V}(\mathrm{Ti}-\mathrm{To})-\mathrm{F}] \Delta \mathrm{t} / \mathrm{C}
$$
fluxes:

The vapour content balance (vapour content, $\mathrm{Cw}, \mathrm{g} \mathrm{kg}^{-1}$ ) included the following

- Transpiration, considered proportional to the insolation and to the saturation deficit, $\mathrm{A}$ $\mathrm{S}+\mathrm{B}$ (Cwis-Cwi). A, g kg ${ }^{-1} \mathrm{~W}^{-1} \mathrm{~m}^{2} \mathrm{~h}^{-1}$; S, insolation, $\mathrm{W} \mathrm{m}{ }^{-2}$; $\mathrm{B}$, water vapour exchange coefficient, $\mathrm{h}^{-1}$; Cwis, saturation inside vapour content, $\mathrm{g} \mathrm{kg}^{-1}$; Cwi, inside vapour content, $\mathrm{g} \mathrm{kg}^{-1}$.

- Vapour losses through the structure, $\mathrm{W}_{1}$ (Cwi-Cwo). $\mathrm{W}_{1}$, water vapour exchange coefficient, $\mathrm{h}^{-1}$; Cwo, outside vapour content, $\mathrm{g} \mathrm{kg}^{-1}$.

- Vapour losses through the open windows, $\mathrm{W}_{2}$ (Cwi-Cwo). $\mathrm{W}_{2}$, water vapour exchange coefficient, $\mathrm{h}^{-1}$. As for temperature, there were two coefficients for two roof apertures, $25 \mathrm{~cm}$ and $70 \mathrm{~cm}$.

This second balance supplied the simulated inside vapour content of each period calculated from the parameters of the previous period, with the following equation $(\Delta t$, time period in hours):

Cwi (next period) $=$ Cwi $+\left[\right.$ A S + B (Cwis-Cwi) $-\mathrm{W}_{1}($ Cwi-Cwo $)-\mathrm{W}_{2}($ Cwi-Cwo) $] \Delta \mathrm{t}$

Simulated relative humidity was finally obtained from the temperature and vapour content of each period. 


\section{Extraction of the coefficients}

Coefficients of the models were extracted with the experimental data (Table 1), using only the first temperature and vapour content as inside climate inputs of the simulation for each data set. The models were run with iteration employing Microsoft ${ }^{\circledR}$ Excel, until reaching the minimum mean absolute difference between the simulated and real inside air temperatures (for the energy balance) and between simulated and real inside relative humidity (for the water vapour balance; only performed in the experiment of heating). The coefficients related to the energy balance were obtained first, and then the coefficients related to the water vapour balance were extracted. All input data were recorded every 5 min.

The measured heat input, outside temperature, relative humidity and solar radiation of each period, the position of windows and thermal screen, the effect of fogging (Perdigones et al., 2008), and the initial inside temperature and vapour content values, were used as inputs to the process; the coefficients $\beta \tau, \mathrm{U}, \mathrm{V}, \mathrm{C}, \mathrm{A}, \mathrm{B}, \mathrm{W}_{1}, \mathrm{~W}_{2}$, were the outputs. The inside air temperature and relative humidity were calculated in each iteration with a constant value of the above coefficients from the values of the last five-minute period. The overall absolute error of the iteration was logged and then a new iteration started with other coefficient values until the error could be reduced no further. Microsoft ${ }^{\circledR}$ Excel SOLVER was used to run the search procedure. This software allows some variables to be altered for the purpose of minimising any given error. Therefore, the software tool searched the best coefficients, assuring that the simulated inside temperature and relative humidity were as close as possible to the real values.

\section{RESULTS}

The results of modelling in the three studies are presented in tables 1, 2 and 3. Table 1 shows the errors in the calculation of temperature and relative humidity. The error in the calculation of temperature was lower than $2.5^{\circ} \mathrm{C}$ in the validation of the model for the three studies (Figure 1). This error was higher in the heating season than in summer, probably since the open window area was variable in the heating season and constant in summer. The error in the calculation of relative humidity was lower than $9 \%$ in the validation of the model (Figure 2), but it was calculated only in one of the three studies.

The coefficients of the model obtained in the three studies were quite different, depending on the type of coefficient (Tables 2 and 3). The value of $\beta \tau$ was 0.31 in the study of heating, 0.62 in the study of ventilation and 0.63 in the study of cooling, but the study of heating was carried out only with night and sunrise data. The difference can be due to the differences in the inclination of the sun; transmittance is higher when radiation is perpendicular to the cover. Probably the mean $\beta \tau$ coefficient of the greenhouse is close to 0.62 .

The coefficient $U$ was obtained in two studies (heating and ventilation), with similar values (13.4 and $14.7 \mathrm{~W} \mathrm{~m}^{-2}{ }^{\circ} \mathrm{C}^{-1}$ ); in the study of cooling a value obtained in the previous heating season was used.

The coefficient $\mathrm{C}$ was different in the three studies $\left(36.2 \mathrm{~kJ} \mathrm{~m}^{-2}{ }^{\circ} \mathrm{C}^{-1}\right.$ in heating, $136.3 \mathrm{~kJ} \mathrm{~m}^{-2}{ }^{\circ} \mathrm{C}^{-1}$ in ventilation and $75.9 \mathrm{~kJ} \mathrm{~m}^{-2}{ }^{\circ} \mathrm{C}^{-1}$ in cooling). Since $\mathrm{C}$ is the heat capacity of the greenhouse, differences probably are due to the fact that the energy input affects to different volumes of the greenhouse in the process. In the process of heating (with air heaters), the energy input mainly increases the temperature of the inside air, 
with very small increases in the structure and soil. On the contrary, in the study of diurnal ventilation, insolation increases the temperature of inside air, structure and soil, so the higher greenhouse volume involved probably produces a higher value of the $C$ coefficient. Anyway, high variations in the value of $C$ produced small variations in the resulting temperatures, and also small differences in the error of the model.

Differences were high in the values obtained for the $\mathrm{V}$ coefficients (energy losses through the open windows). This coefficient is probably the weakest part of the model, since the simplifications involved are important. A simple and linear addition of the wind in the equation of energy losses decreased the temperature error from $2.3^{\circ} \mathrm{C}$ to $1.8^{\circ} \mathrm{C}$ in the study of ventilation.

However, in each study, the coefficients obtained with the data set for 2001/02 worked reasonably well in 2002/03 (with the error values mentioned above). With this kind of model, the calculation of the coefficients with data from at least one whole season is probably required to achieve a reasonable level of error in the following season. In our opinion, the main advantage of the method of modelling is the possibility of fitting the coefficients with the tool SOLVER of Microsoft ${ }^{\circledR}$ Excel in each greenhouse, an easy method for both scientist and growers, using the data of the previous season. Similar models require the determination of many coefficients by regression.

\section{CONCLUSIONS}

- With the model used, the error in the calculation of temperature was lower than $2.5^{\circ} \mathrm{C}$, and the error in the calculation of relative humidity was lower than $9 \%$, in the validation of the model for three independent studies.

- The calculation of the coefficients with data from at least one whole season is probably required to achieve a reasonable level of error in the following season, but this process can be done for each specific greenhouse.

- The main advantage of the method of modelling is the possibility of fitting the coefficients with the tool SOLVER of Microsoft ${ }^{\circledR}$ Excel in each greenhouse, an easy method for both scientist and growers.

\section{ACKNOWLEDGEMENTS}

Funding for this research was obtained from the MCYT Spanish project AGL2005-06492-C03-03 "Evaluación de modelos climáticos como elemento de ayuda a la decisión en el diseño de invernaderos" (Evaluation of climate models as a decisionmaking aid for greenhouse design).

\section{Literature Cited}

de Halleux, D. and Gauthier, L. 1998. Energy consumption due to dehumidification of greenhouses under northern latitudes. Journal of Agricultural Engineering Research, 69. 35-42

Körner, O. and Challa, H. 2003. Process-based humidity control regime for greenhouse crops. Computers and Electronics in Agriculture 39, 1-20.

Perdigones, A., García, J.L., Romero, A., Rodríguez, A., Luna, L., Raposo, C. and De la Plaza, S. 2008. Cooling strategies for greenhouse in summer: control of fogging by pulse width modulation. Biosystems Engineering 99(4), 573-586. 
Spanomitsios, G. K. 2001. Temperature control and energy conservation in a plastic greenhouse. Journal of Agricultural Engineering Research 80 (3), 251-259.

Zolnier, S., Gates, R. S., Buxton, J., Mach, C. 2000. Psychrometric and ventilation constraints for vapor pressure deficit control. Computers and Electronics in Agriculture 26, 343-359.

de Zwart, H.F. 1997. A simulation model to estimate prospectives of energy saving measures in horticulture. Acta Horticulturae, 443: 119-127

\section{$\underline{\text { Tables }}$}

Table 1. Results of modelling in three independent studies (heating, ventilation and cooling) performed in the same greenhouse. Mean absolute errors of the model.

\begin{tabular}{|c|c|c|c|c|c|}
\hline Experiment & $\begin{array}{c}\mathrm{N}^{0} \text { days } \\
\text { (Fitting) } \\
2001 / 02\end{array}$ & $\begin{array}{c}\mathrm{N}^{0} \text { days } \\
\text { (Validation) } \\
2002 / 03\end{array}$ & $\begin{array}{c}\text { Data } \\
\text { Period }\end{array}$ & $\begin{array}{c}\text { Model error } \\
\text { (Fitting: } \\
\text { T, }{ }^{\circ} \mathrm{C} / \\
\text { RH, \%) }\end{array}$ & $\begin{array}{c}\text { Model error } \\
\text { (Validation: } \\
\text { T, }^{\circ} \mathrm{C} / \\
\text { RH, \%) }\end{array}$ \\
\hline Heating & 70 & 48 & $\begin{array}{l}\text { October-May } \\
\text { (night and } \\
\text { sunrise) }\end{array}$ & $\begin{array}{c}1.2 / \\
5.7\end{array}$ & $\begin{array}{c}2.1 / \\
8.8\end{array}$ \\
\hline Ventilation & 170 & 72 & $\begin{array}{l}\text { October-May } \\
\text { (diurnal) }\end{array}$ & $\begin{array}{c}2.0 / \\
-\end{array}$ & $\begin{array}{c}2.3 / \\
-\end{array}$ \\
\hline Cooling & 118 & 97 & $\begin{array}{c}\text { June- } \\
\text { September }\end{array}$ & $\begin{array}{c}1.1 / \\
- \\
\end{array}$ & $\begin{array}{c}1.2 / \\
- \\
\end{array}$ \\
\hline
\end{tabular}

Table 2. Results of modelling in three independent studies performed in the same greenhouse. Coefficients of the energy balance (without thermal screen). Periods of five minutes.

\begin{tabular}{|c|c|c|c|c|c|}
\hline Experiment & $\beta \tau$ & $\begin{array}{c}\mathrm{U} \\
\left(\mathrm{W} \mathrm{m}^{-2}{ }^{\circ} \mathrm{C}^{-1}\right)\end{array}$ & 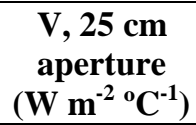 & 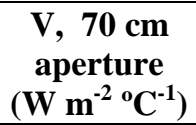 & $\begin{array}{c}\mathrm{C} \\
\left(\mathrm{kJ} \mathrm{m}^{-2}{ }^{\mathrm{o}} \mathrm{C}^{-1}\right)\end{array}$ \\
\hline Heating & 0.31 & 13.4 & 2.6 & 19.5 & 36.2 \\
\hline Ventilation & 0.62 & 14.7 & 18.2 & 32.2 & 136.3 \\
\hline Cooling & 0.63 & $\begin{array}{c}14.8 \text { (not } \\
\text { obtained in the } \\
\text { process) }\end{array}$ & - & 86.2 & 75.9 \\
\hline
\end{tabular}

$\mathrm{Ti}($ next period $)=\mathrm{Ti}+[\mathrm{H}+\beta \tau \mathrm{S}-\mathrm{U}(\mathrm{Ti}-\mathrm{To})-\mathrm{V}(\mathrm{Ti}-\mathrm{To})-\mathrm{F}] \Delta \mathrm{t} / \mathrm{C}$

Table 3. Results of modelling: coefficients of the mass balance (without thermal screen). Periods of five minutes.

\begin{tabular}{|c|c|c|c|c|c|}
\hline Experiment & $\begin{array}{c}\mathbf{A} \\
\left(\mathbf{g ~ k g}^{-\mathbf{1}} \mathbf{W}^{-\mathbf{1}}\right. \\
\left.\mathbf{m}^{\mathbf{2}} \mathbf{h}^{\mathbf{- 1}}\right)\end{array}$ & $\begin{array}{c}\mathbf{B} \\
\left.\mathbf{( h}^{-\mathbf{1}}\right)\end{array}$ & $\begin{array}{c}\mathbf{W}_{\mathbf{1}} \\
\left.\mathbf{( h}^{-\mathbf{1}}\right)\end{array}$ & $\begin{array}{c}\mathbf{W}_{\mathbf{2}} \\
\left.\mathbf{( h}^{-\mathbf{1}}\right)\end{array}$ & $\begin{array}{c}\mathbf{W}_{\mathbf{2}} \\
\left.\mathbf{( h}^{-\mathbf{1}}\right)\end{array}$ \\
\hline Heating & 0.018 & 0.28 & 0.12 & 0.61 & 2.28 \\
\hline
\end{tabular}




\section{Figures}

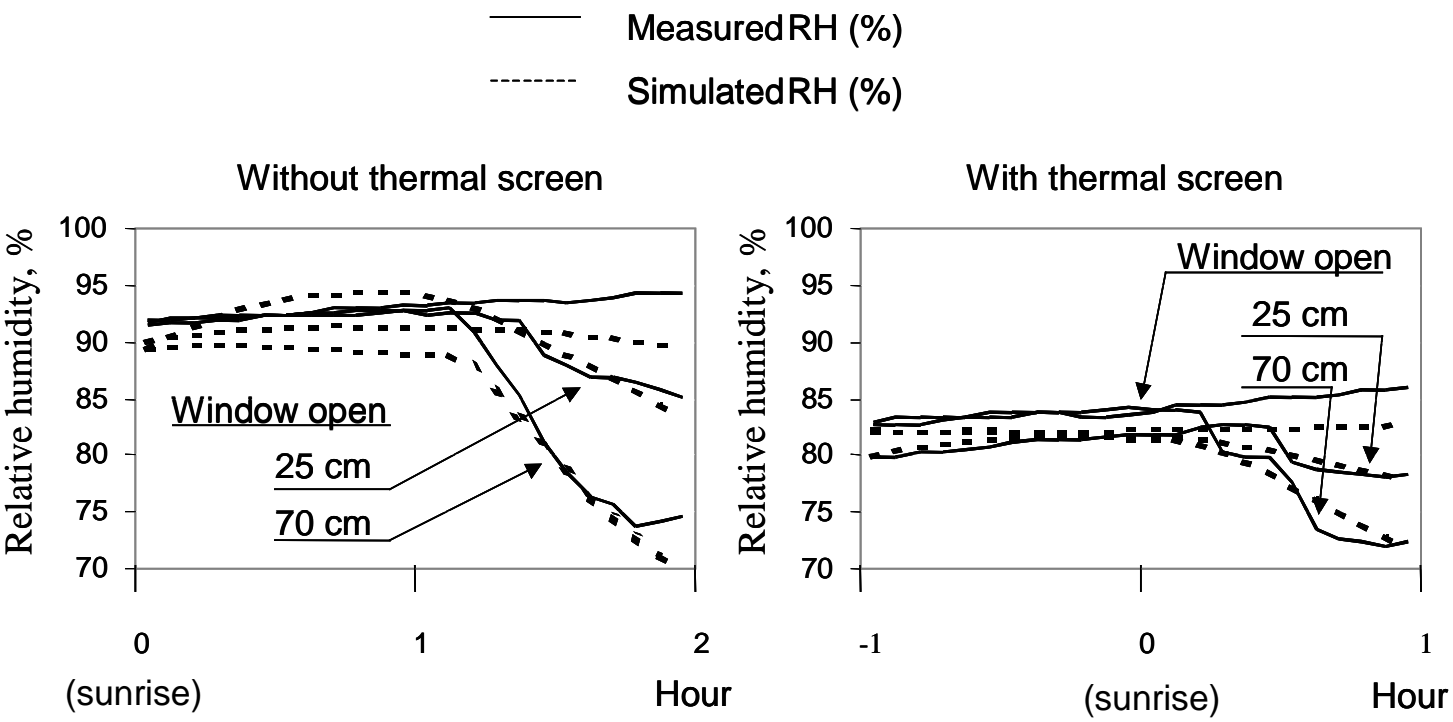

Fig. 1. Measured and simulated values of inside relative humidity, along two hours about sunrise, in the study devoted to greenhouse heating. Experimental tests with and without thermal screen, combined with tests without window apertures, and with apertures of $25 \mathrm{~cm}$ and $70 \mathrm{~cm}$. Each curve is the average of 10 days

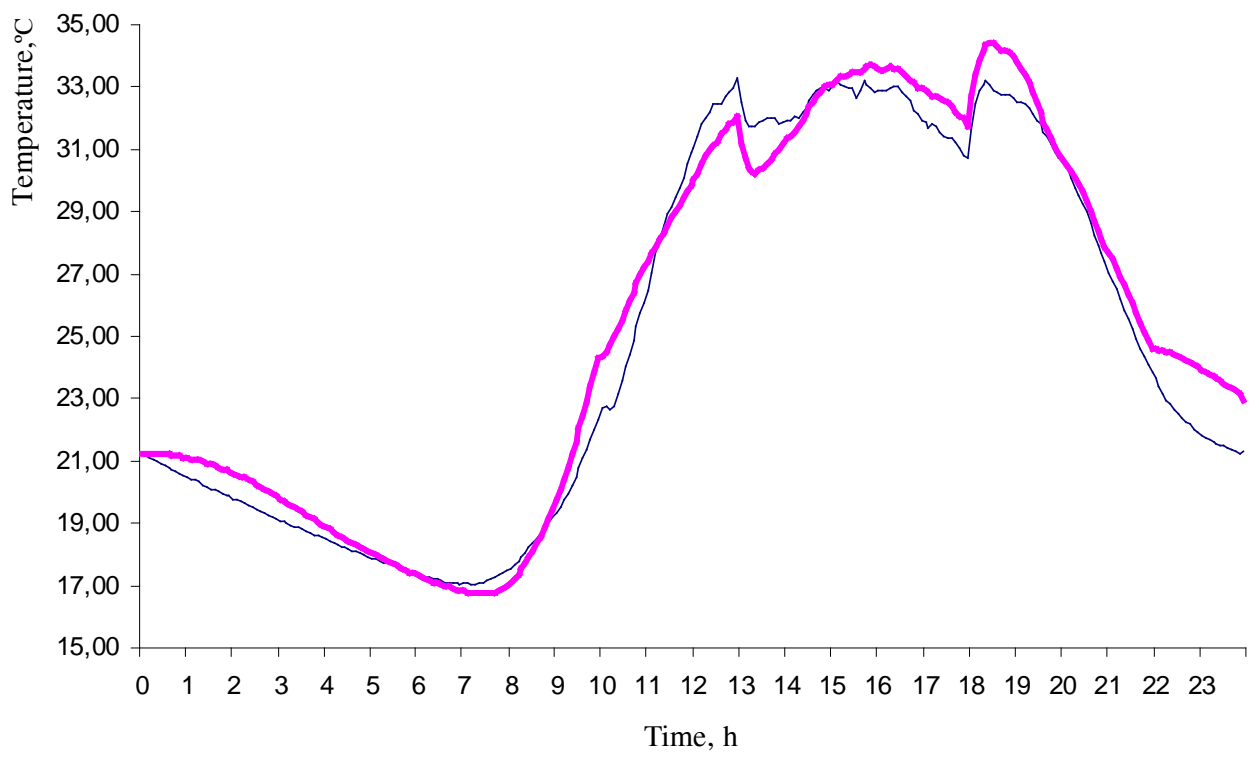

Fig. 2. Measured (-) and simulated $(-$ ) values of temperature, along 24 hours, in the study devoted to greenhouse cooling. Experimental tests with ventilation, shadethermal screen and fogging. Each curve is the average of 10 days 